\title{
LA DESMOVILIZACIÓN Y LA REINSERCIÓN DE LOS VENCIDOS A LA VIDA NACIONAL: LOS REALISTAS EN EL CONFLICTO POR LA INDEPENDENCIA DE VENEZUELA

\section{Demobilization and Reintegration of the Defeated into National Life: Realists within the Conflict for the Independence of Venezuela}

A desmobilização e a reinserção dos vencidos à vida nacional: os realistas no conflito pela Independência da Venezuela

\author{
Francisco José Alfaro Pareja (Venezuela) \\ Universidad Simón Bolívar \\ franciscoalfaropareja@gmail.com
}

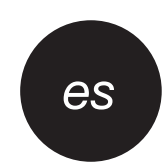

\section{RESUMEN}

Este artículo busca ofrecer una mirada poco estudiada de los conflictos de la Independencia, que parte del caso de Venezuela: el proceso de perdón y reinserción de los vencidos en la vida nacional. Para ello, trato, desde la historia de la paz, los casos de cinco realistas notables: uno de ellos indígena defensor de la causa del rey; otro español, dos veces amnistiado; otro, un militar venezolano criollo que hizo una labor importante por la educación de la república; otro, último marqués de Venezuela en favor del realismo y luego de la independencia y, finalmente, la hermana mayor de El Libertador, Simón Bolívar. A lo largo de la historia de la paz los reincorporamos a nuestra conciencia histórica con una concepción equilibrada y conflictiva.

\section{en}

\section{ABSTRACT}

This article offers a non-academic point of view of the conflicts of the independence of Venezuela: the process of forgiveness and reintegration of the defeated into national life. For this reason, I narrate, from peace history, the cases of five notable realists: one is an indigenous advocate of the King's cause; another one is a Spaniard, who has been pardoned twice; another, a Venezuelan military who greatly contributed to education in the Republic; another one, the last marquis of Venezuela who was in favor of realism and independence; and the other is Simón Bolívar's, The Liberator, older sister. Throughout the history of peace, the readers are part of our historic conscience with a balanced and conflictive understanding.
PALABRAS CLAVE: conflicto, paz, violencia, reinserción, realistas, independencia de Venezuela.
KEYWORDS: Conflict, peace, violence, reintegration, realists, independence of Venezuela.

\section{por}

\section{RESUMO}

Este artigo procura oferecer um olhar pouco estudado dos conflitos da Independência, que parte do caso da Venezuela: o processo de perdão e reinserção dos vencidos à vida nacional. Para isto, tento, desde a história da paz, os casos de cinco realistas notáveis: um deles indígena defensor da causa do rei; outro espanhol, duas vezes anistiado; outro, um militar venezuelano crioulo que fez uma labor importante pela educação da república; outro, último marquês da Venezuela em favor do realismo e logo após da independência e, finalmente, a irmã mais velha do Libertador, Simón Bolívar. Ao longo da história da paz os reincorporamos a nossa consciência histórica com uma concepção equilibrada e conflitiva.

\section{PARA CITAR ESTE ARTÍCULO/TO CITE THIS ARTICLE/PARA CITAR ESTE ARTIGO:}




\section{INTRODUCCIÓN}

Francisco José Alfaro Pareja a patriotas y realistas a lo largo de toda su duración. Sin embargo, y tal como lo plantea el historiador Tomás Straka (2007, p. 4), dicha historia ha sido contada por la mitad, y fue omitida la voz de los vencidos, en este caso la de los realistas. Una vez se inclina definitivamente la balanza en favor del bando patriota, muchos de los realistas amparados bajo el paraguas del Tratado de Regularización de la Guerra suscrito en 1820 (Castellanos, 1998, pp. 97 y 98) zarparon a otros destinos, se reinsertaron en la vida civil de Venezuela o, si habían sido combatientes, pudieron ser asimilados por las fuerzas de la nueva República. No obstante, el relato de estos procesos, donde las capacidades para la paz fueron preponderantes, ha quedado oculto detrás del telón de la llamada guerra de independencia.

La llamada "historia oficial", "nacional" o "patria" ha equiparado la palabra conflicto a la palabra violencia $\mathrm{y}$, por ende, también las regulaciones violentas y su recreación - en discurso épico- a la totalidad del conflicto de la Independencia. Por ello, este proceso se conoce mayormente como guerra de Independencia. A pesar de que el historiador venezolano Germán Carrera Damas (1983, pp. 18-20) ha planteado que el conflicto de la independencia se trata de un proceso político del cual la guerra es una de sus expresiones, reconoce que la visión unidimensional de la violencia es un elemento perturbador de nuestra conciencia histórica (Carrera Damas, 2006, p. 279). Por ello, la independencia debe ser definida como "conflicto", ya que, a lo largo de su duración, implicó interacciones complejas entre regulaciones pacíficas y violentas (Alfaro Pareja, 2014b, pp. 191-193).

Como parte de este interés, la historia de la paz surge como área de estudio transdisciplinar, que busca potenciar la recreación de acontecimientos pasados, tales como las regulaciones pacíficas, los momentos y espacios de paz en la historia dentro de la complejidad. Y es que la paz, señala el historiador y filósofo Francisco A. Muñoz (2001, p. 39), no es un objetivo utópico que se concreta con un tratado, sino un proceso vivencial y dinámico. Además, es un fenómeno imperfecto, porque interactúa permanentemente con instancias de violencia. Con esto, no se desconoce la violencia presente en algunos conflictos, más bien se asume su complejidad producto de la interacción con regulaciones pacíficas (Muñoz, 2004, p. 165). Recordemos que una de las directrices de la historia de la paz es, tal como lo recuerdan Muñoz y López Martínez (2000, pp. 48 y 49), desvelar las instancias en que se producen las relaciones entre la paz y la violencia, así como establecer sus relaciones causales y sus mediaciones. Una de ellas es la reinserción de los vencidos.

El conflicto por la independencia de Venezuela se extendió entre 1810 y 1846, año en el que mediante el Tratado de Reconciliación, Paz y Amistad, España reconoce a Venezuela y cesa definitivamente el conflicto. Sin embargo, desde 1833, implicó el desarrollo de un proceso de paz a través de las relaciones diplomáticas entre ambos Estados, donde los actores, algunos de los cuales potenciaron en el pasado la violencia, ahora potenciaban sus capacidades para la paz (Alfaro Pareja, 2014a, p. 193). Estas capacidades también se incrementaron en el interior del territorio gracias también, en parte, a que realistas y patriotas compartían entonces el espacio ideológico del liberalismo político, fundamentalmente en varios puntos, que destaca Mateucci (1994, p. 879): valoración del individuo y de su racionalidad, el rechazo al absolutismo y el cuestionamiento a verdades sagradas. A partir de ahí, el respeto a las capitulaciones, a la vida de los prisioneros y heridos en batalla y a los preceptos establecidos en las amnistías fue una garantía que permitió la reinserción exitosa en la vida nacional de un gran número de realistas.

En este artículo, se examina el proceso de reinserción de algunos de ellos, una vez Venezuela consolida su independencia. Todos ellos individuos que participaron en el conflicto de la emancipación. Todas ellas voces silenciadas por la "historia oficial". Dionisio Cisneros, indígena defensor de la causa del rey, quien defendió fieramente la causa absolutista a través del método de guerra de guerrillas y quien se benefició de una amnistía promovida directamente por José Antonio Páez, presidente de Venezuela y también accidentalmente su compadre. José Arizábalo y Orobio, militar profesional, quien, después de haber zarpado en el proceso de capitulación y amnistía después de la derrota realista en la batalla del lago de Maracaibo, regresó a Venezuela, conspiró de manera armada a través de la guerra de guerrillas y fue nuevamente amnistiado por el Gobierno nacional después de un proceso de desgaste enorme. Feliciano Montenegro y Colón, militar venezolano criollo al servicio de la causa realista, quien, luego de ocupar cargos 
de relevancia castrense hasta 1821, regresa del exilio a Venezuela en la cuarta década del siglo XIX, convencido de la causa liberal y desarrollando una importante labor por la educación de los jóvenes en Caracas. Francisco Rodríguez del Toro, criollo y último marqués de Venezuela, quien en un proceso zigzagueante de apoyos a causas políticas distintas que fueron desde el absolutismo, pasando por el juntismo y la independencia republicana, se reinsertó de manera más o menos exitosa en la vida política. Finalmente, el caso de María Antonia Bolívar ha sido quizá el más polémico por lo que implicaba, por una parte, ser mujer y defensora activa de la causa del rey y, por otra, hermana de Simón Bolívar, el principal cabecilla del movimiento rebelde y figura posterior de culto y mitificación.

\section{MARCO TEÓRICO}

\section{EL CONFLICTO INDEPENDENTISTA VENEZOLANO DESDE LA HISTORLA DE LA PAZ}

El análisis de las regulaciones pacíficas entre patriotas y realistas en el conflicto por la independencia de Venezuela desde la historia de la paz, y en general en Hispanoamérica, es prácticamente nulo. Los estudios que se han realizado son tangenciales y escasos. La historia de la paz es un área con avances casi inexistentes. Su escaso desarrollo se debe a la enorme influencia de la "historia oficial", repotenciada hoy desde las instancias de poder político y, además, por el escaso desarrollo del área matriz, los estudios para la paz y los conflictos.

El análisis de los conflictos políticos de los siglos XIX y XX en Venezuela ha sido fundamentalmente tratado desde la disciplina de la historia. Y, sin lugar a dudas, el conflicto por la independencia de Venezuela es el tema de mayor análisis por la historiografía y de mayor manipulación por la "historia oficial". No obstante, si algo tienen en común ambas perspectivas, es que los estudios de este conflicto se han planteado mayoritariamente desde una perspectiva de la violencia. ${ }^{1}$ En la "historia oficial" o "patria", uno de los aspectos que la identifica es el exagerado interés demostrado por la "guerra" de Independencia, con una visión romántica en las ideas

1 Esta tendencia de la disciplina de la historia también formó parte, hasta hace pocas décadas, de los propios estudios de paz, los cuales se centraron en sus inicios en los aspectos violentos de los conflictos y en cómo evitarlos. Es a partir de libros como el de Anatol Rapoport titulado Peace: An idea whose time has come, publicado en 1992 por Ann Arbor, University of Michigan Press, que los estudios de paz comenzaron a entenderse a si mismos desde una perspectiva de paz. políticas y la épica en su relato, así como con un enfoque que tradicionalmente ha sido homogéneo en su interpretación, que, según la historiadora venezolana Inés Quintero, da cuenta de una serie de desviaciones, carencias $\mathrm{u}$ omisiones debido a

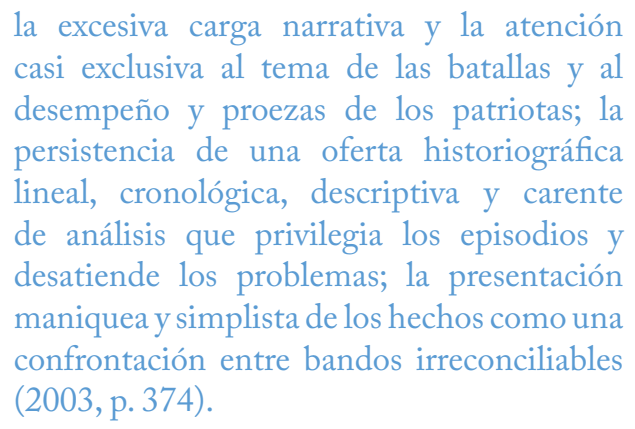

Asimismo, la "historia oficial" relata de manera predominante la faceta político-militar del hecho y sus protagonistas y no estudia los otros ámbitos, las facetas y los personajes del proceso; sobredimensiona los hechos y personajes del conflicto como cuna de nuestra historia e ignora o tergiversa el pasado precolombino y colonial; sataniza u omite a los realistas y españoles del conflicto de Independencia en vez de estudiarlos en su justa medida; se cuenta "desde arriba" en lugar de ser una historia que se cuente "desde todas partes"; tergiversa el pasado inmediato para justificar el presente, sus estructuras político-culturales y los actores que las generan. Carrera Damas considera este último punto el más peligroso, porque se ha llegado incluso a la manipulación de momentos históricos que ya han sido estudiados por la historiografía de manera rigurosa. La mejor expresión es el llamado Culto a Simón Bolívar (2005, pp. 108113), que es un elemento ineludible para explicar la factibilidad de hechos que, en teoría, no hubiesen podido ser llevados adelante por seres humanos comunes. Así, el discurso político se hizo discurso historiográfico y de esta manera ingresó en los manuales de enseñanza y se convirtió en paradigma inmóvil de la historia nacional desde el siglo XIX hasta nuestros días.

Por su parte, la historiografía se erigió desde hace ya varios años como herramienta rigurosa para el análisis de los hechos del pasado. Sin embargo, a la hora de estudiar el conflicto de la independencia de Venezuela, si bien no cae en las desviaciones, omisiones o tergiversaciones de la "historia oficial" e incluso plantean nuevos problemas del mismo tema, sí cae en las carencias, en una específicamente: sigue haciendo el abordaje, mayoritariamente, desde el enfoque de la violencia del conflicto,
La desmovilización y la reinserción de los vencidos a la vida nacional: los realistas en el conflicto por la Independencia de Venezuela
I Panorama

I pp.51-65

I Volumen 10

I Número 18

I Enero-junio

I 2016 
Francisco José Alfaro Pareja

Panorama I pp. 51-65। Volumen 10 I Número 18 । Enero-junio I 2016 I Asimismo, destaca Muñoz, esta historia de la paz es imperfecta, ya que permite identificar aquellos espacios $\mathrm{e}$ instancias en los que se pueden detectar acciones que

La historia de la paz, tal como lo plantean los historiadores Francisco A. Muñoz y Beatriz Molina Rueda, es aquella que nos permite reconocer, rescatar y destacar las regulaciones y transformaciones pacíficas de los conflictos, y todos los factores y actores involucrados en ellas. Es la que se encarga de rescatar e historiar las cosmovisiones de paz de la sociedad, es decir, aquellos aportes reales hechos por la paz para "ordenar, organizar y construir las relaciones armónicas entre los individuos y los grupos que constituyen una sociedad" (Muñoz y Molina Rueda, 1998, p. 13). Se habla de re-conocimiento de la paz en la historia, porque en lo profundo de nuestras conciencias reconocemos la paz, porque la paz es y ha sido un hecho de nuestra cotidianidad y, en ocasiones, fungiendo como paz negativa o positiva, ha transformado o regulado conflictos de mediana y gran intensidad. En resumen, la historia de la paz imperfecta busca ser, por una parte, una historia de los espacios, momentos, actividades y actores que han fomentado o fomentan desde la cotidianidad la convivencia, el reconocimiento, la cordialidad, el encuentro, la interdependencia y el ahorro de energía en su sentido más general $y$, por otra, una historia de las regulaciones y transformaciones pacíficas de los conflictos no cotidianos de mayor complejidad y magnitud. generan paz, a pesar de que estén en contextos en los que existen los conflictos y la violencia. La historia de la paz, y su vocación transdisciplinar, le permiten interactuar, realizar y recibir aportes hacia y desde diversas ramas del conocimiento, para generar y alimentarse de un saber que necesariamente es complejo y está interrelacionado. Muñoz habla de la necesidad de partir de un campo transdisciplinar para estudiar la paz como respuesta a la complejidad de las dinámicas sociales.

Metodológicamente, el abordaje de la historia de las independencias partiría la matriz unitaria desarrollada por Muñoz et al. (2005, pp. 127-129), la cual implica entender dichos procesos, en su conjunto y complejidad, como conflictos; deconstruir los relatos que han exaltado determinados eventos de violencia; visibilizar y resaltar las acciones de paz desarrolladas por diversos actores a lo largo del conflicto; identificar las mediaciones que permitieron iniciar negociaciones y procesos de diálogo, disminuir la violencia y concretar armisticios, regularización de la guerra, capitulaciones, tratados.
En Venezuela, en el periodo en el que se desarrolla el conflicto por la Independencia, identificamos, a lo largo de la historia de la paz, la interacción compleja y permanente de diversas formas de paces y violencias. Algunas de ellas dentro del conflicto, otras después de su finalización armada y otras más allá de él. Esto, sin lugar a dudas, permite reconocer nuevas instancias y espacios de paz en la historia, todo ello a partir de la potenciación de capacidades para la paz de diversos en actores (Alfaro Pareja, 2013, pp. 35-36). En el caso del presente estudio, implicaría el análisis de las capacidades que permitieron la desmovilización o la reinserción de realistas icónicos en la vida nacional en el periodo del posconflicto.

\section{LA REINSERCIÓN DE DIONISIO CISNEROS Y JOSÉ ARIZÁBALO Y OROBIO: REALISTAS DE LA ÚLTIMA OFENSIVA ARMADA}

Después de la batalla de Carabobo en junio de 1821, que le da una importante victoria al Ejército Libertador y que consolida prácticamente de hecho la independencia de Venezuela, no se produjo capitulación debido a la huida de gran parte de los realistas, pero sí el respeto de la regularización de la guerra hacia los vencidos, heridos y prisioneros del Ejército del rey, tal como lo testimonia Miguel de la Torre, jefe del Ejército realista en Venezuela, a Simón Bolívar, y donde manifiesta que 
dicho bando ha actuado "dando pruebas nada equívocas de que hace renacer las virtudes sociales que habían desaparecido por el enardecimiento de las pasiones que han desolado estos fértiles países" (De Armas Chitty, 1971, p. 92). Sin embargo, algunos combatientes quedaron realengos.

Para 1823, los patriotas habían sentenciado la victoria bajo un horizonte de optimismo con la victoria en la batalla naval del lago de Maracaibo, donde nuevamente, y apegados al Tratado de Regularización de la Guerra de 1820, se respetaron los derechos de los vencidos, prisioneros y heridos en combate. El propio Francisco Tomás Morales, último jefe de las fuerzas realistas en Venezuela, reconoce que cerraban el conflicto con "la capitulación más honrosa que había obtenido ningún Ejército Real de Ultramar" (Lemmo y Carrera Damas, 1971, pp. 1142 y 1143).

Ese mismo año se produce la toma de puerto Cabello, y se arría la bandera del último bastión realista en el fuerte de dicha plaza. El historiador Rafael María Baralt señala que justo después de esta acción "concluye la guerra de independencia. En adelante, no se emplearán las armas de la república, sino contra guerrillas de forajidos que la tenacidad peninsular armó y alimentó por algún tiempo" (Páez, 1990, p. 226). Uno de esos guerrilleros era Cisneros, quien venía ejerciendo acciones en los valles inmediatos a Caracas desde que quedó realengo en la derrota de Carabobo de 1821. Cisneros lideraba bandas armadas en favor de la causa real, y aterrorizaba con el pillaje, el asesinato, el reclutamiento forzado y el saqueo a los hacendados del Tuy, Santa Lucía, Baruta y Petare (Palacios Herrera, 1989, pp. 12 y 95).

Pero ¿quién era José Dionisio Cisneros? Cisneros era un indígena venezolano que tenía contacto con el hombre blanco. Según Herrera Palacios (1995, pp. 19 y 29), era un "indio de calidad", que era un rango exclusivamente social conferido a quien lo obtenía por herencia, posición o servicios. De oficio arriero, cuasi analfabeta y posteriormente soldado, hizo el servicio militar en las filas realistas, y se especializó en la guerra de guerrillas. $\mathrm{Su}$ conocimiento del contexto boscoso y de sus exigencias, así como una veneración del rey Fernando VII y de un catolicismo sincrético, hizo que se convirtiera en el bastión de mayor resistencia realista en Venezuela.
Después de uno de los ataques más violentos que se produjeron contra la población de Petare y Baruta en diciembre de 1824, un destacamento del Apure sorprendió a este grupo y mató a ocho de ellos. No obstante, el general José Antonio Páez, haciendo uso de las facultades que le confería el Estado de Asamblea o de Ley Marcial, indultó a los seguidores de Cisneros, siempre y cuando se presentaran a las autoridades republicanas en un mes. Pero esta medida no fue escuchada. El 15 de agosto de 1825, el general en jefe Santiago Mariño informó al secretario de Guerra que la facción de Cisneros había sido destruida, pero su jefe había escapado (Bencomo Barrios, 1997b, pp. 831 y 832).

Con Cisneros fugado, la reacción realista vería su mayor esplendor y coordinación con la llegada de un oficial español a sus costas: José Arizábalo y Orobio. Con la excusa de que era prófugo de España, pidió refugio en Venezuela. Arribó al puerto de la ciudad de La Guaira en 1826. Este militar, que estuvo bajo el mando del comandante realista Tomás Morales en la batalla de Maracaibo, tuvo que zarpar rumbo a Cuba producto de la capitulación realista del 4 de agosto de 1823, bajo el juramento de no volver a levantar las armas contra la República de Colombia.

A principios de 1827, Arizábalo recibió de Simón Bolívar, presidente de Colombia - y quien había retornado a Venezuela después de cinco años liderando la independencia en el sur de América一, el ofrecimiento de un puesto en el Ejército republicano. Sin embargo, Arizábalo y Orobio solo acepta reinsertase en la vida civil. Meses más tarde, el español abandona Caracas, se interna en la cadena del interior de la cordillera de la Costa y transita por los pueblos de Villa de Cura, Parapara, San Sebastián y Ortiz. Allí da un giro inesperado y comienza a lanzar proclamas firmadas, escribe cartas a diversos oficiales, prodiga grados militares en nombre del rey de España y se relaciona con los guerrilleros más denotados (Bencomo Barrios, 1997a, p. 225).

El fortalecimiento de estos movimientos realistas tuvo quizá su origen en la ineficacia del Ejército republicano producto de las pugnas internas en que se sumergía el departamento de Venezuela y, a su vez, en las diferencias que presentaba con el Gobierno central de Colombia en Bogotá desde 1825.
La desmovilización y la reinserción de los vencidos a la vida nacional: los realistas en el conflicto por la Independencia de Venezuela
I Panorama I pp. 51-65 I Volumen 10 I Número 18 I Enero-junio | 2016 
Francisco José Alfaro Pareja

Panorama I pp. 51-65। Volumen 10 I Número 18 । Enero-junio I 2016 I

(

En una tónica dirigida a restablecer la tranquilidad en toda Venezuela, Bolívar, tal como lo hiciese Páez años antes, en decreto del 12 de enero de 1827, indulta de toda pena al realista Cisneros y a quienes lo acompañaban a cambio de deponer las armas, renunciar a la vida errante $\mathrm{y}$ abstenerse de efectuar acciones hostiles contra las tropas y los habitantes. Pero estos intentos fracasarían. Así, se sustituirían las negociaciones de paz por la pacificación a la fuerza. Bolívar ordenaría, en el mes de mayo de 1827, la creación de una Columna de Operaciones compuesta por 806 efectivos militares, para hacerle frente a Cisneros (Palacios Herrera, 1989, p. 148).

Arizábalo y Orobio, quien había recibido el cargo de jefe de las armas de su majestad en Venezuela, le escribe a Dionisio Cisneros a fin de unir fuerzas, evitar el diálogo con los patriotas y emprender acciones bélicas solo contra las fuerzas militares y no contra la población civil (tal como planteaban los preceptos establecidos en la regularización de la guerra) y señaló que se preparaba una insurrección realista dirigida y apoyada desde Puerto Rico. Sin embargo, afirma Palacios Herrera (1989, pp. 155-168), Cisneros no aceptaba más autoridad que la suya. Pronto, Arizábalo declararía a Dionisio Cisneros "enemigo del rey" y lo destituye de su cargo como "segundo jefe de las fuerzas de su majestad en Venezuela”.

El 11 de enero de 1828 se hizo presente la tan esperada flotilla de barcos españoles desde Puerto Rico, compuesta por una fragata de 64 cañones, un bergantín de 50 y otro de 20 , los cuales aparecieron ante el puerto de La Guaira. Sin embargo, Arizábalo y sus seguidores nunca lograron coincidir con las naves guerreras que zarparon de regreso a la isla el 22 de febrero. El historiador Tomás Straka recrea su situación y la de sus seguidores de la siguiente manera:

$$
\begin{aligned}
& \text { De hecho, parece más un profeta } \\
& \text { conduciendo por las montañas del Tuy } \\
& \text { y Guatopo a una califa de desarrapados; } \\
& \text { un Moisés buscando la promesa de una } \\
& \text { salvación improbable [...] Arizábalo sabe } \\
& \text { que así son las cosas en Venezuela, que la } \\
& \text { gente le da vivas a quien pueda conseguirle } \\
& \text { algo y eso, en 1828, cuando lo que abunda } \\
& \text { es la miseria, ya es cualquier cosa (2009, } \\
& \text { pp. 25). }
\end{aligned}
$$

Luego de dos años de penurias, sufrimientos, muertes, espera y esfuerzos vanos, el 12 de junio de 1829 José Arizábalo y Orobio propuso al general Lorenzo Bustillo una entrevista para evitar más derramamiento de sangre. A partir de aquí es interesante destacar el trato que recibe el militar realista por parte de los republicanos. El teniente de navío José María Machado, encargado de la comandancia en ausencia temporal del general patriota Bustillos, le ofrece su amistad y reconocimiento.

En sus memorias, José Arizábalo y Orobio relata que el teniente de navío salió a recibirlo con una nutrida comitiva, hizo formar la tropa y le rindieron honores. Describe:

Todos en brazos me habían ayudado a echar
pie a tierra [...] el uno me presentaba al
barbero y peluquero; el otro con sus manos
lavaba mis pies; el otro rasgaba mis miserables
andrajos y cubría mis carnes decentemente;
y todos proferían exclamaciones tales como:
"Este es el hombre extraordinario de nuestro
siglo" (Palacios Herrera, 1989, p. 183).

Después de unas horas de descanso, republicanos y realistas se sentaban a tomar el café, los anfitriones brindaron por Bolívar y por Páez. Arizábalo, fiel a su monarca, dijo que solo podía brindar por el rey Fernando VII, y así lo hizo. Para su sorpresa, todos contestaron con un “viva”. Relata su sensación de la siguiente manera: "Más placer tuve en oír victoriar a su majestad por sus propios enemigos que en haber ganado una batalla" (Palacios Herrera, 1989, p. 183).

La capitulación que se suscribiría representaría otro reto para el Tratado de Regularización de la Guerra de 1820, porque no se trataba de un soldado español cualquiera que hacía la guerra contra Colombia, sino de un militar amnistiado, que había jurado no volver a levantar las armas contra la República en 1823, y que en 1827 había jurado la Constitución de Colombia y se había comprometido a llevar adelante actividades del ámbito civil. Dos meses habrían de transcurrir hasta el día 18 de agosto de 1829 , cuando se suscribió la capitulación de José Arizábalo y Orobio con el general republicano Lorenzo Bustillos.

Este documento establecía, en parte su articulado, la reinserción en la vida nacional (o en algún territorio español) en libertad, libertad a los prisioneros de guerra, 
olvido perpetuo y protección igualitaria ante la ley. La palabra "perpetuo olvido" está presente en el artículo 4 de la capitulación. Pero la capitulación a Arizábalo y los suyos va más allá. Se les da la posibilidad en cuanto a reinserción en la vida nacional, es decir, la inclusión de los vencidos y el trato equitativo ante la ley sin resentimientos; es una de las medidas que garantiza el sostenimiento de un proceso de paz en el tiempo. En el artículo 6, se ofrece amnistía a toda persona que haya apoyado o colaborado con la causa realista emprendida por Arizábalo y sus soldados, incluso la hacen extensiva a Cisneros y sus partidarios en dos meses a término de presentación (Páez, 1990, pp. 400 y 401). José Arizábalo y Orobio zarpó nuevamente desilusionado hacia tierras americanas españolas, pero otra vez amnistiado y con vida. Arizábalo, el dos veces perdonado.

Una vez disgregada Colombia, el general Páez como máxima autoridad civil y militar de Venezuela, empleará el acercamiento progresivo a Cisneros como estrategia, incluso se convertirá en su compadre al bautizar a uno de sus hijos y darle una buena educación, el cual quedó cautivo en una operación armada de la Columna de Operaciones. Este nexo formado por el "compadrazgo" se convertirá en una "mediación” entre Cisneros y Páez para el inicio de conversaciones de paz directas con el objeto poner fin a las regulaciones violentas.

A principios de 1831, Cisneros contaba ya con muy poco apoyo y fuerza. Muchos de los que lo acompañaban fueron desertando o se acogieron a los indultos dados por el Congreso en junio de 1830. E1 9 de agosto de 1831 sorpresivamente Cisneros envía un oficio a Páez para buscar regular y resolver el conflicto por vías pacíficas. Reconociendo el gesto de paz de Páez al adoptar y hacerse cargo de su hijo capturado, manifiesta: “Tenga miseración para este querido hijo que en sus manos está, mírelo como quien es que se lo agradeceré a S. E., mire S. E. que tiene hijo también" (1990, pp. 201 y 202). El 21 de agosto el Consejo de Gobierno en sesión extraordinaria autorizó al Ejecutivo para conceder a Cisneros y a sus acompañantes de lucha un perdón absoluto o un pasaporte a ultramar si prefería salir de Venezuela, siempre que abandonaran su actitud. El general Páez se convence de que la única forma de resolver este conflicto es mediante un camino distinto de la violencia.

Finalmente, Páez manifiesta su intención de ir a verlo personalmente a los valles del Tuy para conversar, lo cual fue previsto para el 29 de septiembre de 1831. Pero el general perdería su viaje, ya que Cisneros no se presentó a la cita. Pocas semanas después, en una carta del realista al coronel Stopford, se disculpaba por su ausencia, puesto que supuso se le tendería una celada. No obstante, manifestó, esta vez sí, su intención de negociar directamente con Páez. El general retomó inmediatamente su viaje desde la capital y el 17 de noviembre del mismo año, junto con unos pocos oficiales, se abrirá paso entre el monte para llegar directamente al cantón de Dionisio Cisneros en la montaña. Es decir, el presidente de la república, al más puro estilo del caudillo latinoamericano, se hace cargo de este asunto en persona, acción que sorprenderá a Edward Stopford, comandante británico asimilado al Ejército republicano y asignado a la conducción de la Columna de Operaciones contra Cisneros (Palacios Herrera, 1989, pp. 213 y 214).

Ese día, luego de hartos esfuerzos y de años de sugestión, el general Páez finalmente logra rendir a Cisneros no por la fuerza sino por la persuasión, no por la violencia sino mediante el diálogo. E1 22 de noviembre de 1831 se suscribe en el catón de Lagartijo la capitulación entre el coronel Dionisio Cisneros y el general José Antonio Páez.

En esta ocasión, Páez no solo respaldó la aplicación de la amnistía a Cisneros, sino que le otorgó su espada como emblema de hermandad. Y como símbolo de confianza no solo se le incorporaba en el Ejército republicano conservando su mismo grado, sino que se le designó a él y a sus tropas como custodios de los valles del Tuy, la misma zona que durante años habían asolado. Pero muchos oficiales patriotas y miembros del Gobierno no estuvieron satisfechos con esta última medida de incorporarlo en el Ejército republicano. La violencia generada por Cisneros lo había convertido en el Fra Diávolo del realismo y, al mismo tiempo, la propaganda en su contra en un ser deshumanizado que había que eliminar. Este calificativo, señala la historiadora Anne Morelli (citada por Koch, 2007, pp. 290-291), se le da al enemigo a fin de hacerlo acreedor de los peores calificativos y convertirlo en una especie de supervillano. De modo que su reinserción sería muy cuesta arriba.

La ausencia de arrepentimiento y rectificación por parte del ahora coronel de la república, fortalecerá el resentimiento de los militares que lo rodean y no su perdón. La reinserción de Cisneros no será exitosa, pues
La desmovilización y la reinserción de los vencidos a la vida nacional: los realistas en el conflicto por la Independencia de Venezuela Venezuela

. 
Francisco José Alfaro Pareja

Panorama I pp. 51-65। Volumen 10 I Número 18 | Enero-junio I 2016 I Bolívar (para los realistas, el principal cabecilla de los facciosos; para los patriotas, El Libertador). Había nacido el 1 de noviembre de 1777 en Caracas. María Antonia había sido obligada a emigrar al Caribe por parte de su propio hermano menor, Simón, cuando en 1814 la ofensiva realista liderada por José Tomás Boves y Francisco Rosete estaba por retomar la capital (De Sola Ricardo, 1997, p. 494).

María Antonia, consideraba que era innecesaria su salida de la capital, ya que su defensa de las ideas realistas era pública y conocida, por lo que no tendría ningún problema en ser acogida por las nuevas autoridades. No obstante, el simple hecho de ser la hermana del principal líder faccioso de Venezuela y Nueva Granada ponía su vida y la de su familia en peligro. Además, para 1814, la "guerra a muerte", proclamada por su hermano contra españoles y canarios y la "guerra contra los blancos" o "guerra de colores", proclamada por el caudillo José Tomás Boves contra los criollos mantuanos, había potenciado la violencia a los máximos niveles del conflicto entre patriotas y realistas.

De Curazao a La Habana, María Antonia no podía creer la situación repentina de desarraigo que estaba pasando con sus cuatro hijos menores de edad y la pérdida de todas sus propiedades, por las ocurrencias de un grupo de personas, entre las cuales se encontraba su hermano como principal dirigente. Además, le preocupaba el prestigio de su honor y que su intachable postura realista fuera confundida solo por ser la hermana de Bolívar. Así lo asevera la historiadora Inés Quintero, quien ha estudiado la vida de la mayor de las Bolívar. En carta a la Real Audiencia de Caracas, del 28 de agosto de 1816, María Antonia Bolívar explica su actuación ante el conflicto en Venezuela y asevera: "Mis débiles esfuerzos se emplearon útilmente en salvar una porción de españoles, que existen actuálmente en esa capital y sus inmediaciones, exponiendo mi propia seguridad a la furiosa saña del insolente populacho" (Quintero, 2008, pp. 40).

En 1823, cuando ya Venezuela estaba definitivamente en manos patriotas, regresa al país bajo la protección de su propio hermano. Podría decirse que María Antonia, ya en Caracas, se reinsertó rápidamente en la nueva vida republicana. En poco tiempo, y luego de dejar atrás las diferencias con Simón, se convirtió en la encargada de recuperar los bienes perdidos por la familia, pagar las cuentas que debía y cobrar las deudas de las que eran acreedores los Bolívar. Según Quintero, con el poder otorgado a María Antonia por su hermano, como hija mayor y de mejor grado que los demás sucesores, se convirtió en la dueña de casi todas las propiedades que pertenecían al mayorazgo de los Bolívar. 
Reinsertarse en la vida nacional, bajo la protección de Bolívar, no fue algo tan difícil al principio. Total, su hermano era El Libertador de cinco naciones. Sin embargo, los tiempos volvieron a hacerse difíciles para María Antonia, ya no por ser realista sino por ser, nuevamente, la hermana de Bolívar. Y es que en 1830 Venezuela se separa de Colombia y su hermano Simón es proscrito. María Antonia debía enfrentar nuevamente una situación bastante incómoda por ser la hermana de Bolívar. En Caracas y Bogotá, se creó una animadversión hacia Bolívar después de que instaló un gobierno dictatorial, porque se le acusaba de querer autocoronarse rey de los Andes.

María Antonia pasó de la noche a la mañana de ser la hermana mayor de E1 Libertador a ser la hermana del usurpador de Colombia o la pariente del tirano. Con Bolívar muerto en diciembre de 1830 y defenestrado de la historia de la joven República de Venezuela, las actuaciones de María Antonia se basaron fundamentalmente en el ámbito privado de la recuperación de las posesiones de la familia. A partir de entonces, su férreo temperamento, su motivación por recuperar lo que por herencia le pertenecía y las disputas con sus hermanos para repartir los bienes de Bolívar fueron sus principales aliados para moverse en un ambiente social relativamente hostil a su apellido.

Solo en 1842, con la repatriación de los restos mortales de Bolívar desde Colombia a Venezuela, ordenada por el ahora presidente José Antonio Páez, se iniciaría lo que se conoce hoy como el Culto a Bolívar. Sin embargo, ese periodo que a María Antonia le hubiese resultado beneficioso desde el punto de vista de la reconciliación —en cuanto "el pueblo" se reencontraba con Bolívar y, en consecuencia, con los Bolívar- no pudo ser vivido por la caraqueña que murió precisamente ese año, el $7 \mathrm{de}$ octubre. De hecho, podríamos decir que la reinserción rigurosa de María Antonia Bolívar en la historiografía nacional ha empezado solo a partir de 2003, cuando Inés Quintero publica su polémica obra La criolla principal: María Antonia Bolívar, hermana de El Libertador, justo en una época cuando se resucita el culto inmaculado a Bolívar a través de una nueva versión de la "historia oficial”. Y, quizá, una de las razones para que esta reinserción historiográfica se haya realizado tan tardíamente es la posición política que había asumido la caraqueña con respecto a Simón Bolívar. Quintero señala: “¿Cómo resolver el inconveniente de que su propia hermana fuese enemiga de los patriotas? ¿De qué manera podía solventarse que la hermana mayor del Libertador fuese partidaria del rey de España?” (2008, p. 185).

El caso de Feliciano Montenegro y Colón fue otro de aquellos realistas venezolanos de renombre que logra reinsertarse en la vida republicana después del conflicto de la independencia de Venezuela. Montenegro y Colón nace en Caracas el 9 de junio de 1781. Su posición fue bastante privilegiada, puesto que su padre era un funcionario político español en Caracas y su madre pertenecía al mantuanaje caraqueño. Es decir, era una mezcla de blanco peninsular y blanco criollo. Montenegro y Colón pudo aprovechar su condición para estudiar letras e iniciar la carrera militar, justo en el periodo en el que comenzaba a granjearse el conflicto por la independencia de Venezuela. En 1798, ingresa como cadete en el Batallón de Veteranos de Caracas y un año más tarde ingresa en el Regimiento de la Reina. A partir de ahí, continúa su carrera militar en España y participa en diversas misiones, incluso en la lucha contra las tropas napoleónicas que invadieron la Península.

En 1810, Montenegro y Colón, ya de rango capitán primero, es enviado en misión a Venezuela para trabajar en la Secretaría de Guerra. Sin embargo, ante la inestable situación política que se debatía entre la defensa de los derechos de Fernando VII y la independencia, decide regresar secretamente a España. Este hecho que será conocido como la "huida de Montenegro" lo perseguirá el resto de su vida, pues se le acusará de la presunta extracción de recursos y documentos de dicha oficina. Lo cierto es que Montenegro y Colón, realista convencido, regresará a Venezuela solo hasta 1816, una vez que tuvo noticias de que las revueltas habían sido pacificadas por el Ejército expedicionario de Pablo Morillo, para cumplir funciones oficiales.

En Venezuela, desempeñó la presidencia del Consejo de Guerra de Caracas, la Comandancia de los Valles del Tuy, la Jefatura Militar y Gobernación de Barcelona, la Gobernación de Maracaibo y, finalmente, fue el Jefe de Estado Mayor de las fuerzas realistas que combatieron en la batalla de Carabobo (Bencomo Barrios, 1997c, pp. 233 y 234). Sin lugar a dudas, era uno de los jefes realistas de mayor peso en Venezuela durante el conflicto de la independencia. $\mid \begin{aligned} & \text { La desmovilización } \\ & \text { y la reinserción } \\ & \text { de los vencidos a }\end{aligned}$
la vida nacional:

los realistas en

el conflicto por la

Independencia de Venezuela
I Panorama

I pp. 51-65

I Volumen 10

I Número 18

I Enero-junio

I 2016 
Francisco José Alfaro Pareja

Panorama I pp. 51-65। Volumen 10 I Número 18 । Enero-junio I 2016 I

No obstante, y más allá de los numerosos documentos con los que buscaba justificar su conducta de exrealista respetuoso de la ley y el derecho de gentes, la labor más importante que realizó Montenegro y Colón fue la que dedicó a la educación y a las ciencias humanísticas en Venezuela. En 1836, Montenegro funda en Caracas el Colegio Independencia, el cual busca dar una educación de calidad a los jóvenes de la naciente República. El Colegio preveía gratuidad para aquellos jóvenes pobres que mostraran interés por estudiar y alimentos y libros para aquellos pobres que no estuviesen internos. Es autor, además, de diversas obras de geografía, buenas costumbres, educación, doctrina cristiana e historia. En su libro Geografía venezolana, el cuarto tomo titulado Apuntes históricos está referido a la historia de Venezuela. Sobre este libro, Franceschi (1994, pp. 83-85) reconoce que Montenegro y Colón aborda la historia contemporánea de su tiempo de una manera en la que trata de mantener el equilibrio en los juicios y en el tratamiento de temas muy polémicos (incluso en nuestros días). Todo esto tomando en cuenta que muchos protagonistas de dichos acontecimientos hacían vida pública en Venezuela y tenían mucho poder.

Si bien en Venezuela el acogimiento de esta obra fue tibio, no solo por haber sido escrita por un coronel del Ejército realista, sino porque muchos de sus contemporáneos tenían un miedo terrible a ciertas verdades que podrían desvelar la imperfecta y variada conducta de cada uno de los personajes políticos y militares, en una época turbulenta de continuos cambios de autoridades, partidos, líderes y tendencias, algunos personajes reconocerán el mérito de la obra. Uno de ellos era el general Páez, el hombre fuerte de Venezuela y antiguo adversario, quien, en gesto de la voluntad conciliadora que ya había demostrado con Arizábalo y Orobio y con Cisneros, le confió la educación de sus hijos. En su Autobiografía, Páez señala que Montenegro y Colón "presentó a Venezuela el nunca buen ponderado trabajo que modestamente llamó Compendio de Geografía, añadiéndole una completa relación de la contienda revolucionaria; libro que es la mejor autoridad sobre los sucesos de aquella época” (Páez, 1990, p. 175).

Que el propio general Páez haya calificado este estudio como "buen ponderado" es algo digno de destacar. Asimismo, su Colegio Independencia, por el cual recibió tantas críticas, fue un proyecto que al final de su vida le ocasionó, a él y su familia, más preocupaciones que satisfacciones. Nuevamente el general Páez en su Autobiografía reconoce el mérito de este caraqueño al emprender la instalación del Colegio y su modelo educativo innovador para luchar con "una juventud indócil, 
cuyos mismos padres no comprendían el valor del servicio que él se proponía hacerles a ellos y a la patria” (Páez, 1990, p. 177). Montenegro y Colón morirá en el olvido y la relativa pobreza debido a los problemas financieros generados por su Colegio el 6 de septiembre de 1853 a los 72 años.

Finalmente, otro destacado caso de reinserción fue el de Francisco Rodríguez del Toro, IV marqués del Toro. Nacido en Caracas en 1761, y como primogénito del III marqués, hereda un título nobiliario que lo colocaba en el lugar más alto de la sociedad colonial, obligado a cumplir deberes y obligaciones inherentes de su investidura. Desde la muerte de su padre en 1787, Del Toro se caracterizó siempre por ser un irrestricto defensor de la monarquía, del buen orden, de la religión católica y la sociedad estamental basada en el honor como miembro de las principales instituciones y órdenes de la sociedad colonial. Pero a partir de la invasión napoleónica a España y el pronunciamiento de los mantuanos de Caracas, la vida del marqués iniciará un periplo zigzagueante entre los bandos en conflicto.

Fiel a su investidura, en 1806, participó en el despliegue militar contra los intentos de invasión llevados a cabo por Francisco de Miranda, bajo las órdenes del capitán general Manuel Guevara Vasconcelos. Posteriormente, participó en la llamada Conspiración de los Mantuanos en 1808, por la cual sufrió arresto domiciliario hasta 1809 cuando es indultado (Naranjo de Castillo, 1997, p. 997). Cuando se producen los sucesos del 19 de abril de 1810, donde se instala la Junta Defensora de los Derechos de Fernando VII, el marqués se convierte en su primer jefe de tropas, con la misión infructuosa de poner fin al imperio de la tiranía y convencer a los habitantes de Coro de la causa de abril. Más sorprendente aún es el nuevo giro del marqués al convertirse en diputado del nuevo Congreso de Venezuela y estar entre los firmantes de la declaración de independencia en julio de 1811.

Posteriormente, en los primeros días de mayo de 1812, ante el inminente fracaso del primer proyecto republicano y la reacción realista de Domingo de Monteverde, el marqués desertó justo mientras comandaba una misión que le ordenara el general Francisco de Miranda dirigirse a los llanos del sur a levantar un cuerpo de caballería. Del Toro y su hermano Fernando aparecieron refugiados en Cumaná y al poco tiempo huyeron angustiosamente a las Antillas en un periplo que los llevó hasta Trinidad (Quintero, 2005, pp. 107-143).

A partir de ahí, se inicia todo un proceso de rectificación donde el marqués y su hermano buscaron por diversas vías, tanto directamente como a través de los buenos oficios de sus hermanos y su esposa, en Cumaná, Caracas y Madrid, explicar su conducta y solicitar el perdón de su majestad y la devolución de sus propiedades en Venezuela. Entre 1812 y 1820, no muy esperanzado en obtener el perdón real y sin intención de regresar a la revuelta Venezuela, el marqués se había instalado en Trinidad, donde adquirió algunas propiedades y una hacienda de cacao en las afueras de Puerto España con la ayuda económica de su hermano Pedro, quien se había casado con una acaudalada mujer en Madrid y había heredado una importante fortuna a su muerte. Sin embargo, con la llegada del Gobierno liberal a España en 1820, la publicación de la Constitución de 1812 y la orden de negociar la paz con los rebeldes, así como la noticia de Carabobo en 1821, cambia el panorama completamente para el marqués, quien decide regresar en 1822 a Venezuela, donde estaban todas sus propiedades y donde "su amigo", Simón Bolívar, le había pedido desde 1817 retornar al país, pero sin enviarle siquiera una respuesta. Total, como señala Quintero (2005, pp. 173-175), algún provecho debía obtener del hecho de haber sido parte de la gloriosa revolución de abril de 1810 .

Sin embargo, el marqués Del Toro estaba claro que a su llegada podría enfrentar duras críticas por su deserción y huida en 1812, lo cual pudiese poner en entredicho su compromiso con la causa independentista. ¿Cómo borrar esa escena del imaginario de los caraqueños? Afortunadamente, tan traumático fue el conflicto en decesos y migraciones forzadas, y tan cercano era el afecto de Bolívar por Del Toro, que al menos al principio no tuvo que sortear ese obstáculo. Tendría que sortear sí, al igual que le tocó a María Antonia Bolívar, el impacto del progresivo desmembramiento de la sociedad estamental que se había establecido con la Constitución de Colombia de 1821 y que no reconocía ningún fuero, que había sancionado la libertad de expresión, la igualdad legal de los colombianos, la virtud armada y la eliminación gradual de la esclavitud.

En 1823, es nombrado intendente de Venezuela, la más alta responsabilidad del Poder Ejecutivo, encargado de
La desmovilización y la reinserción de los vencidos a la vida nacional: los realistas en el conflicto por la Independencia de Venezuela

I Panorama I pp.51-65 I Volumen 10 I Número 18 I Enero-junio I 2016 
Francisco José Alfaro Pareja

Panorama I pp. 51-65। Volumen 10 I Número 18 । podrían ser motivo de especulación, pero hablan de la forma en que los humanos gestionan la complejidad en situaciones extremas.
$\mathrm{Al}$ respecto, Straka hace hincapié en que este tipo de microhistorias

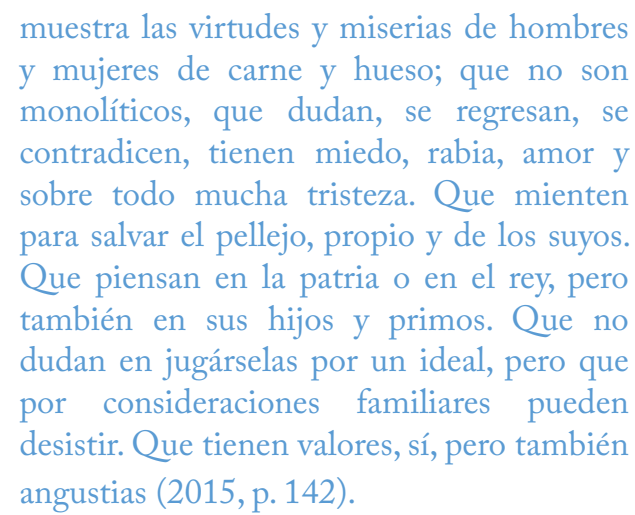

La historia del vencido, que se reinserta en la vida nacional después del conflicto independentista, redimensiona y revalúa los estudios sobre este proceso desde un enfoque más complejo y plural.

\section{CONCLUSIONES}

En Venezuela, al igual que en Hispanoamérica, la independencia ha sido el conflicto de mayor impacto en la conformación de la conciencia histórica de la República. Como todo conflicto de esta índole, implicó la interacción entre regulaciones pacíficas y violentas a lo largo de todo su desarrollo. La tarea de rescatar las regulaciones pacíficas representa un reto académico por la excesiva manipulación que ha hecho la historia oficial en cada uno de los países y por el relato incompleto de la historiografía. Recrear dichos procesos a partir de una historia de la paz imperfecta puede influir decididamente en el empoderamiento pacifista de las personas.

En este artículo, hemos tratado una pequeña parte de dicho conflicto: los procesos de desmovilización y reinserción de un grupo de realistas notables en la vida nacional en Venezuela. Los casos analizados representan solo una pequeña muestra de la gran cantidad de realistas que debieron reinsertarse en la vida nacional una vez el conflicto se inclinó en favor de las fuerzas patriotas. Si bien no se pueden hacer deducciones, es de suponer que más allá de las particularidades estos procesos fueron complejos. Más aún, los de aquellos que habiendo militado en uno de los partidos defendieron las banderas contrarias en algún momento.

En todos los casos analizados, destaca la desconfianza con que los vencedores siempre vieron a los vencidos, 
más allá incluso de la actitud que estos pudiesen haber asumido a partir de su reinserción en la vida nacional. Esto fue aún más cuesta arriba debido a lo encarnizado y polarizado que fue el conflicto independentista en determinadas etapas. Sin embargo, los valores liberales que compartían patriotas y realistas, y que fueron plasmados en el Tratado de Regularización de la Guerra de 1820, facilitaron no solo el proceso de paz entre Venezuela y España que finaliza en 1846 con la suscripción de un tratado, sino los procesos imperfectos de perdón, olvido y reinserción de realistas en la vida nacional dentro del territorio venezolano.

Es importante destacar que para el momento en que se producen los procesos de reinserción de Cisneros, Arizábalo y Orobio, Montenegro y Colón, Bolívar y Rodríguez del Toro, las principales premisas para que el proceso fuera exitoso eran las del perdón y el olvido por ambas partes, basados en principios liberales de la época. Señala Guédez (2004, pp. 58 y 59) que al finalizar un conflicto es necesario el compromiso de vencedores y vencidos por un fin superior. Para superar el pasado y conquistar el porvenir, se requiere el perdón y el olvido. El primero es esfuerzo de no recordar y el compromiso de reconstruir algo, el segundo es más profundo y no deja huella. Hoy en día, se habla más bien de memoria y reconciliación, que implican una conducta corresponsable. Estas no se viven como experiencias posconflicto, sino como factores explícitos de denuncia y afirmación de diferencias, así como de aplicación de justicia. De esta manera, lo está planteando, por ejemplo, la comisión negociadora en el proceso de paz que se desarrolla en el conflicto colombiano (Centro Nacional de Memoria Histórica, 2013, p. 18).

En el caso de las tropas de Arizábalo y Orobio y de Dionisio Cisneros, interesa destacar la voluntad de resolver el conflicto de manera pacífica. Principalmente, porque muchos de estos actores quizá hubiesen tenido miles de razones para utilizar la violencia como último recurso. Pero, en cambio, potenciaron sus capacidades para hacer la paz y actuaron en consecuencia. No sin antes, claro, ir venciendo la desconfianza y el miedo entre las partes.

Aunque Arizábalo y Orobio no se reinserta en la vida nacional venezolana, esto es por decisión propia. Se le deja partir hacia puerto español con todas las garantías que la internalización de los valores liberales del Tratado de Regularización de la Guerra conllevó. Por su parte, la reinserción que se hace con Dionisio Cisneros es mucho más compleja. Aunque Cisneros fue incorporado en el Ejército republicano conservando su rango, jamás pudo reconciliarse de lleno con la República ni con sus víctimas. Como dice Larrañaga (2006, pp. 194 y 195), perdonar es extinguir los sentimientos de odio contra el otro, es apagar la llama. La paz interior y la paz social solo vienen con el perdón. Pero, ciertamente, en Cisneros, su reinserción no vino acompañada del arrepentimiento y cambio de actitud. Por su parte, Páez había errado al darle el protectorado de las mismas poblaciones sobre las cuales cometió diversos y continuados crímenes. Al final, la aplicación de la justicia llegaría, aunque con retraso y de manera violenta.

Los casos de Feliciano Montenegro y Colón, Francisco Rodríguez del Toro y María Antonia Bolívar permiten tener solo una muestra de la complejidad de los conflictos políticos y de cómo fue posible obtener resultados exitosos aunque imperfectos en los procesos de reinserción de los vencidos en la vida nacional. En Montenegro y Colón, se observa cómo un exmilitar realista de alto rango, activo en el conflicto de la independencia, es favorecido por una amnistía y se reinserta en la vida nacional y hace una importante labor pedagógica y realiza aportes en el ámbito de las ciencias sociales. Muchos lo verán con recelo; pero otros, incluso los propios jerarcas del Ejército patriota, le reconocerán su actitud ejemplar y sus méritos.

En María Antonia Bolívar, la complejidad será mayor, porque la existencia de una defensora activa del realismo será opacada por la historia de Simón Bolívar, la cual no podía aceptar contradicciones de este calibre. El proceso de María Antonia será traumático por las acciones de su hermano y por las acciones en contra de él en distintas etapas del conflicto. Finalmente, el caso de Francisco Rodríguez del Toro muestra cómo la complejidad del conflicto hizo que un actor de la nobleza caraqueña emprendiera un periplo que lo llevaría a defender de manera zigzagueante banderas del todo contrapuestas para terminar como prócer de la independencia y la república en Venezuela.

No obstante, el mayor reto historiográfico de hoy, más allá de rescatar y relatar la historia de los vencidos y sus procesos de reinserción, es promover la inserción de sus historias en la conciencia histórica nacional de una manera compleja, imperfecta, conflictiva y plural.
La desmovilización y la reinserción de los vencidos a la vida nacional: los realistas en el conflicto por la Independencia de Venezuela
I Panorama I pp.51-65

I Volumen 10 I Número 18 I Enero-junio | 2016 
Francisco José

Alfaro Pareja

\section{REFERENCIAS}

1. Alfaro Pareja, F. (2013). El conflicto por la independencia de Venezuela: una historia de paz imperfecta. Politeia, 36(51), 33-49.

2. Alfaro Pareja, F. (2014a). Capacidades para la paz en las negociaciones para el reconocimiento de la independencia de Venezuela por parte de España (1833 y 1846). Revista de Paz y Conflictos, 7,175-194.

3. Alfaro Pareja, F. (2014b). El iris de la paz:paz y conflictos en la independencia de Venezuela. Castellón: Publicacions de la Universitat Jaume I.

4. Bencomo Barrios, H. (1997a). José Antonio Arizábalo y Orovio. En Diccionario de historia de Venezuela (t. I, pp. 224-227). Caracas: Fundación Polar.

5. Bencomo Barrios, H. (1997b). José Dionisio Cisneros. En Diccionario de historia de Venezuela. (t. I, pp. 831 y 832). Caracas: Fundación Polar.

6. Bencomo Barrios, H. (1997c). Feliciano Montenegro y Colón. En Diccionario de historia de Venezuela (t. III). Caracas: Fundación Polar.

7. Carrera Damas, G. (1983). La crisis de la sociedad colonial venezolana. Caracas: Monte Ávila.

8. Carrera Damas, G. (2005). En defensa de las bases históricas de la conciencia nacional: esquema para su estudio. Procesos Históricos, 8, 8 .

9. Carrera Damas, G. (2006). Achicar la sentina de la historiografía venezolana. Procesos Históricos, 10. Recuperado de http://www.redalyc.org/ articulo.oa?id=20001014

10. Castellanos, R. R. (1998). La dimensión internacional del Gran Mariscal de Ayacucho. Cumaná:

Panorama I

pp. 51-65।

Volumen 10 I

Número 18 ।

Enero-junio I

2016 I Ediciones de la Gobernación del Estado Sucre.

11. Centro Nacional de Memoria Histórica (2013). ¿Basta Ya! Colombia: memorias de guerra y dignidad. Bogotá: Centro Nacional de Memoria Histórica.

12. De Armas Chitty, J. A. (1971) Carabobo. Caracas: Ernesto Armitano Editor.
13. De Sola Ricardo, I. (1997). María Antonia Bolívar. En Diccionario de historia de Venezuela (t. I). Caracas: Fundación Polar.

14. Vicenc, F. (1998). Cultura de paz y gestión de conflictos. Barcelona: Icaria.

15. Franceschi, N. (1994). Vida y obra del ilustre caraqueño don Feliciano Montenegro y Colón. Caracas: Ediciones de la Alcaldía de Caracas.

16. Guédez, V.(2004). Ética, politica y reconciliación: una reflexión sobre el origen y propósito de la inclusión. Caracas: Criteria Editorial.

17. Koch, P. (2007). La historia oculta del mundo. Barcelona: Bronce.

18. Larrañaga, I. (2006). Sube conmigo: para los que viven en común. Caracas: San Pablo.

19. Lemmo, A. y Carrera Damas, G. (comps.) (1971). Materiales para el estudio de la ideología realista de la Independencia. Anuario, II. Caracas: Instituto de Antropología e historia, Facultad de Ciencias Económicas y Sociales, Universidad Central de Venezuela.

20. Mateucci, N. (1994). Liberalismo. En N. Bobbio, N. Mateucci y G. Pasquino, Diccionario de politica (pp. 875-897). México: Siglo XXI.

21. Muñoz, F. A. (2001). La paz imperfecta ante un universo en conflicto. En F. A. Muñoz (ed.), La paz imperfecta (pp. 21-66). Granada: Universidad de Granada.

22. Muñoz, F. A. (2004). ¿Qué son los conflictos? En B. Molina Rueda y F.A. Muñoz (eds.), Manual de paz y conflictos (pp. 145-170). Granada: Universidad de Granada.

23. Muñoz, F. A. y López Martínez, M. (2000). E1 reconocimiento de la paz en la historia. En F. A. Muñoz y M. López Martínez (eds.), Historia de la paz: tiempos, espacios y actores (pp. 15-49). Granada: Universidad de Granada.

24. Muñoz, F. A. y Molina Rueda, B. (1998). Circunstancias de las cosmovisiones de paz en el Mediterráneo. En F. A. Muñoz y B. Molina Rueda (eds.), Cosmovisiones de paz en el Mediterráneo (pp. 11-28). Granada: Universidad de Granada.

25. Muñoz, F. A., Herrera Flores, J., Molina Rueda, B. y Sánchez Fernández, S. (2005). Investigación de la paz y los derechos humanos desde Andalucía. Granada: Universidad de Granada.

26. Naranjo del Castillo, C. (1997). Francisco Rodríguez del Toro e Ibarra. En Diccionario de bistoria de Venezuela (t. III). Caracas: Fundación Polar. 
27. Páez,J. A. (1990). Autobiografía del general José Antonio Páez. Caracas: Ediciones de PDVSA.

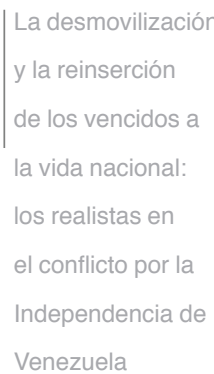

29. París Albert, S. (2009). Filosofía de los conflictos: una teoría para su transformación pacifica. Castellón: Icaria.

30. Quintero, I. (2003). II Congreso Internacional: los procesos de independencia en América española. Montalbán, 36 .

31. Quintero, I. (2005). El último marqués: Francisco Rodríguez del Toro. Caracas: Fundación Bigott.

32. Quintero, I. (2008). La criolla principal: María Antonia Bolivar, la hermana del Libertador. Caracas: Aguilar.

33. Reconocimiento de la Independencia por España (30 marzo 1845). Recuperado de http:// www.anhvenezuela.org/pdf/textos\%20historicos/010064.pdf

34. Straka, T. (2007). La voz de los vencidos: ideas del partido realista de Caracas, 1810-1821. Caracas: Universidad Católica Andrés Bello.

35. Straka, T. (2009). E1 rey no quiere a los blancos. El Desafío de la historia, 1(2), 25-29.

36. Straka, T. (2015). Venturas y desventuras de la nobleza criolla: la república fragmentada. Claves para entender a Venezuela. Caracas: Alfa. 